\title{
Normal Science and Normal Kuhn. Review of Kuhn's Structure of Scientific Revolutions - 50 Years On
}

Editors: William J. Devlin, Alisa Bokulich

Publisher: Springer

Release Date: 2015

Number of Pages: 199

Adam Tamas Tuboly

Institute of Philosophy,

Hungarian Academy of Sciences, Budapest

tuboly.adam@btk.mta.hu

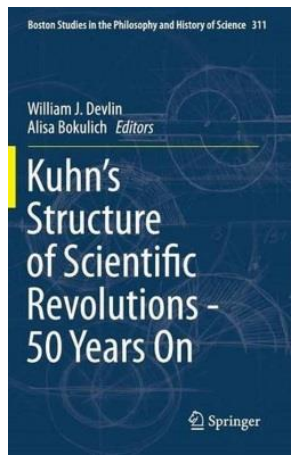

\begin{abstract}
1962 marked an important point in intellectual history not only for historians, philosophers, sociologists and scientists but also for educated laymen. After a long and productive decade Thomas Kuhn published his Structure of Scientific Revolutions as Volume 2 Issue 2 of the International Encyclopedia of Unified Science, edited (after the death of Otto Neurath) by Rudolf Carnap and Charles Morris. 2012 marked another important date-it was the 50th anniversary of Structure's first edition. The many conferences, workshops and presentations were documented in special issues and collections; one of them is Kuhn's Structure of Scientific Revolutions - 50 Years On, edited by William J. Devlin and Alisa Bokulich. The review aims to shed light on the collections relevance for current interdisciplinary studies.
\end{abstract}

Keywords: Thomas Kuhn; Structure of Scientific Revolutions; philosophy of science; normal science; science studies.

1962 marked an important point in intellectual history not only for historians, philosophers, sociologists and scientists, but also for educated laymen. After a long and in many ways productive decade, Thomas Kuhn published his Structure of Scientific Revolutions (SSR hereafter) as Volume 2 Issue 2 of the International Encyclopedia of Unified Science, edited (after the death of Otto Neurath) by Rudolf Carnap and Charles Morris. 2012 marked another important date-it was the 50th anniversary of SSR'S first edition. The many 
conferences, workshops and presentations were documented in special issues and collections; one of them is Kuhn's Structure of Scientific Revolutions - 50 Years On, edited by William J. Devlin and Alisa Bokulich.

50 Years On is an important contribution to the constantly growing literature on Kuhn, along with the history and philosophy of science depicting certain new ways and recasting certain old ways in which we understand them.

Due to the painstakingly detailed examination and reevaluation of logical empiricism that took place in the last two decades, it is quite widely known that some members of the movement, like Philipp Frank and Otto Neurath, pursued interdisciplinary studies. They aimed to utilize knowledge and ideas from physics, mathematics, sociology, economics and psychology emphasizing their deep-rooted interrelatedness. Their reason to do so was the empirical underdetermination of scientific theories: given that empirical data do not determine unambiguously how to build up or choose between rival scientific theories, one shall investigate and keep an eye on various other branches of the sciences.

Logical empiricists are, however, not known for their interdisciplinary or, as one might also say, science studies; it is Thomas Kuhn who, by defeating logical empiricists, became the merger of canons, pushing their unrelated concerns in a common direction. Though the underdetermination of theories was not unknown for Kuhn, he motivated his inquiries in his first book, violating the institutionalized boundaries (The Copernican Revolution, Harvard University Press, 1957), in the following way: since scientific concepts and theories are ideas, they could be investigated from the viewpoint of intellectual history, hence the philosophy of science needs to broaden its viewpoint and perspective.

Though many scholars have argued that the relation between Kuhn, Carnap and logical empiricism should be reevaluated in favor of the latter two (that is, by showing that Carnap's and Kuhn's projects were reconcilable and Kuhn did not kill logical empiricism from their point of view), Jonathan Y. Tsou argues otherwise in his contribution to the volume. His chapter is devoted to the reconsideration of the Carnap-Kuhn connection, and he tried to show that the newly emerged literature against the old thesis of Kuhn killing logical empiricism is just far-fetched. It is argued that "revisionist analyses fail to sufficiently acknowledge that Carnap's linguistic frameworks are logical reconstructions [...], while Kuhn's theory of scientific revolutions is motivated to provide a naturalistic description of scientific change" (p. 52). Thus, says Tsou, the alleged similarities between Carnap's and Kuhn's views turn out to be superficial. 
Tsou might be right about the differences of these scholars' views, but the question is whether a Carnapian point of view could embrace the general narrative of Kuhn. According to the correspondence of Carnap (analyzed famously by George Reisch), he can do that, and according to the bipartite metatheory of logical empiricism (put forward by Thomas Uebel), the naturalistic description of actual scientific developments was just one wing of a broader conception of philosophy of science that was also accepted, besides Frank and Neurath, by Carnap. But more importantly, and it is a different question, Carnap is just one representative of logical empiricism, thus contrasting his views with Kuhn is never enough. Kuhn allegedly contributed to the demise of logical empiricism and not that of Carnap per se.

Besides logical empiricism (or logical positivism and the inevitable break between positivist and post-positivist science) the characterizing ideas and notions of past Kuhn-scholarship were incommensurability and its relation to relativism, truth, and the rationality of science along with progress in science. 50 Years On testifies that many (not all, of course) contemporary philosophers of science are not concerned anymore with these issues (though it should be mentioned that in his chapter Alexander Bird presents some old-fashioned received views). But even if they do, their approach echoes more nuanced and relaxed treatments of these issues.

James A. Marcum, for example, discusses the "the evolving notion and role of the incommensurability thesis" in Kuhn's oeuvre showing the continuously reflexive and intellectually receptive character of Kuhn's accommodation to his critics. By touching also on the question of truth and realism Marcum's chapter brings us to Michela Massimi's contribution who asks such questions as "Was Kuhn some kind of relativist? Did he advocate a form of constructivism? Or was he a mild realist, after all?” (p. 135). She reconstructs Paul Hoyningen-Huene's Kantian realist and Ron Giere's perspectival realist reading of Kuhn and formulates new challenges regarding the Kantian overtones in Kuhn's philosophy. Finally, one of the editors, William J. Devlin presents an account of "truth" in Kuhn's philosophical enterprise. He shows how Kuhn tried to dismiss the notion of "truth"' (taken as the "correspondence theory of truth") altogether from (the philosophy of) science while maintaining that science aims at the knowledge of nature. Devlin argues that Kuhn could overcome this tension by accepting "the claim that science achieves the truth about nature, with the qualification that a new alternative theory of truth is introduced" (p. 161). His new theory is based on a Kantian distinction between phenomenon and the independent world and claims that "science achieves knowledge of nature as the phenomenal world, but does not achieve the truth about nature as the independent world" (p. 162) - hence we got the "phenomenal-world correspondence theory of truth" which seems to be compatible with the Kuhnian enterprise. 
Most of the papers, however, are concerned with such notions of and approaches to SSR that fell off the radar right after its publication. These include normalcy and normal science, the generality and explanatory power of Kuhn's scheme. Alan Richardson formulates some neat worries about the nature and role of philosophy and history of science against a Kuhnian background. He claims that scholars should not "fret so much about the nature of their relationship as they try better to articulate their own explanatory practices” (p. 49).

Cyrus C. M. Mody urges philosophers, historians and sociologists of science to focus on what Kuhn called "normal science" since "if we're still interested in pushing the Kuhnian project forward, then knowing more about what scientists and engineers do all day is fundamental to understanding the structure both of scientific revolutions and of scientific normalcy" (p. 101). The ethnography of practicing scientists shows that Kuhn's notion of normal science is too restrictive and needs an extension. "Normal science," says Mody (p. 96), "achieves many more goals than just the clearing away of anomalies and open questions;" hence normal science demands more attention than revolutionary science if we wish to understand its nature and workings.

The descriptive project of science is the subject of Steven Shapin and Alexander Bird. The former argues that to understand SSR we have to understand first its historical contexts and underpinnings given that it was "produced in a historically specific set of circumstances" (p. 12). Nonetheless, Shapin provides only more or less general insights into the micro cosmos of Kuhn and instead looks at the overall settings of his project. He argues that Kuhn was thought to be anti-scientific, anti-rational and relativistic because he did not celebrate science uncritically for its own sake-Shapin does not assert whether Kuhn tries to present a rational or irrational picture of science. Kuhn just described what he has found in scientific texts and among the practices behind those texts. While for many "science was too precious, and especially too fragile, a flower to be dealt with in an ordinary, matter-of-fact sort of way" (p. 14), Kuhn provided a realistic account in the sense that he has taken at face value what learned from (his so-called Aristotle) experience.

Kuhn is placed in a Hegelian narrative of thesis, antithesis, and synthesis (normal science, anomaly, and paradigm-shift) in Alexander Bird's chapter. By indicating the external-internal debate of philosophers of science, Bird presents a new account of Kuhn's concerns. According to him, Kuhn was an internalist in the sense that he did not deal with general external factors (such as politics, religion etc.) since they do not surface in the normal scientific enterprise. As Shapin and Mody argue for the relevance of normal science, Bird too regards it to be of utmost importance. He also shows that Kuhn took seriously certain external concerns: his cyclic pattern of paradigm-normal- 
science-anomaly-crisis-revolution provides a scheme for understanding and explaining science in general terms.

The last two chapters of the volume focus on influences of and on Kuhn. Brad Wray touches upon the relation between sociology of science and Kuhnwhether there were any influences in any direction. He provides a detailed empirical comparison and reveals some misunderstanding of a highly complex situation. Unfortunately, though such figures as Robert Merton and Bernard Barber are referred to, they do not play a vital role in the chapter despite their serious efforts of promoting and developing sociology of knowledge and science in the United States. The last chapter in the volume is Paul Hoyningen-Huene's “Kuhn's Development Before and After Structure”. It matches the reader's expectations: the author describes Kuhn's early formative years with the neglected influence of Wittgenstein and provides many details concerning the mature Kuhn and his last project, which remained unfinished.

Though the volume contains two more chapters (one from Sherrilyn Roush and one from Rogier De Langhe and Peter Rubens), they are concerned with such general issues (related to Kuhn but discussed without any exegetical or interpretative aims) as the relation between the success and failures of past science to contemporary science and whether they have any bearings on it (Roush) and the difference and relation between theory choice and theory search (De Langhe and Rubens). While their issues are important and their discussions are illuminating, they represent the weakest link in the historical settings of the volume.

Though many more questions could have been covered (like the neglected influences on Kuhn from such figures as Philipp Frank, James Conant and his other Harvard fellows, or the sociological and historical question how Kuhn became "Kuhn"), 50 Years On constitutes a decisive step towards the reevaluation of Kuhn's Structure. It might also lead to new research programs on normal science and its internal/external settings instigating many more interdisciplinary studies. Since normal science is embedded into many ordinary practices with sociological, psychological, economical, anthropological and other cognitive and non-cognitive concerns (such as the taste, customs, hobbies, and interests of scientists and their co-workers) interdisciplinary studies are inevitable if we aim to understand what science was, is, and/or should be.

Supported by The ÚNKP-16-4-II New National Excellence Program of the Ministry of Human Capacities. 


\section{Literature}

Devlin, W.J, Bokulich, A., ed. 2015. Kuhn's Structure of Scientific Revolutions - 50 Years On. Boston Studies in the Philosophy and History of Science. Springer.

Kuhn, T.S. 1962/2012. The Structure of Scientific Revolutions. University of Chicago Press.

Neurath, O., Carnap, R, Morris, Ch.W., ed. International Encyclopedia of Unified Science. The University of Chicago Press. 